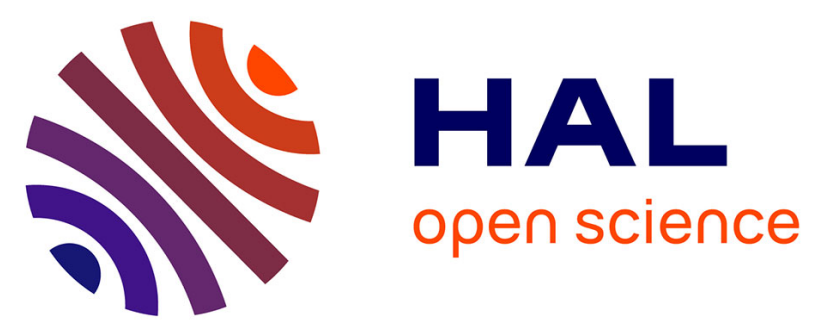

\title{
Aggregation of Plate-like Colloids Induced by Charged Polymer Chains: Organization at the Nanometer Scale Tuned by Polymer Charge Density
}

Yasine Sakhawoth, Laurent Michot, Pierre Levitz, Anne-Laure Rollet, Juliette Sirieix-Plénet, Daniel Hermida Merino, Natalie Malikova

\section{To cite this version:}

Yasine Sakhawoth, Laurent Michot, Pierre Levitz, Anne-Laure Rollet, Juliette Sirieix-Plénet, et al.. Aggregation of Plate-like Colloids Induced by Charged Polymer Chains: Organization at the Nanometer Scale Tuned by Polymer Charge Density. Langmuir, 2019, 35 (33), pp.10937-10946. 10.1021/acs.langmuir.9b00939 . hal-02298408

\section{HAL Id: hal-02298408 \\ https://hal.sorbonne-universite.fr/hal-02298408}

Submitted on 26 Sep 2019

HAL is a multi-disciplinary open access archive for the deposit and dissemination of scientific research documents, whether they are published or not. The documents may come from teaching and research institutions in France or abroad, or from public or private research centers.
L'archive ouverte pluridisciplinaire HAL, est destinée au dépôt et à la diffusion de documents scientifiques de niveau recherche, publiés ou non, émanant des établissements d'enseignement et de recherche français ou étrangers, des laboratoires publics ou privés. 
This document is confidential and is proprietary to the American Chemical Society and its authors. Do not copy or disclose without written permission. If you have received this item in error, notify the sender and delete all copies.

\section{Aggregation of plate-like colloids induced by charged polymer chains: organisation at the nanometer scale tuned by polymer charge density}

\begin{tabular}{|r|l|}
\hline Journal: & Langmuir \\
\hline Manuscript ID & la-2019-00939y.R1 \\
\hline Manuscript Type: & Article \\
\hline Date Submitted by the & n/a \\
\hline Complete List of Authors: & $\begin{array}{l}\text { sakhawoth, yasine; Sorbonne Université, CNRS, Laboratoire PHENIX; } \\
\text { École Supérieure de Physique et de Chimie Industrielles de la Ville de } \\
\text { Paris } \\
\text { Michot, Laurent; Sorbonne Université, CNRS, Laboratoire PHENIX } \\
\text { Levitz, Pierre; Sorbonne Université, CNRS, Laboratoire PHENIX } \\
\text { Rollet, Anne-Laure; Sorbonne Université, CNRS, Laboratoire PHENIX } \\
\text { Sirieix-Plénet, Juliette; Sorbonne Université, CNRS, Laboratoire PHENIX } \\
\text { Hermida-Merino, Daniel; Netherlands Organization for Scientific } \\
\text { Research, Chemistry } \\
\text { Malikova, Natalie; Sorbonne Université, CNRS, Laboratoire PHENIX }\end{array}$ \\
\hline
\end{tabular}

\section{SCHOLARONE Manuscripts}




\title{
Aggregation of plate-like colloids induced by
}

\section{charged polymer chains: organisation at the}

\section{nanometer scale tuned by polymer charge density}

\author{
Yasine Sakhawoth ${ }^{\dagger}$ Laurent Michot, ${ }^{\dagger}$ Pierre Levitz, ${ }^{\dagger}$ Anne-Laure Rollet, ${ }^{\dagger}$ Juliette \\ Sirieix-Plenet, $^{\dagger}$ Daniel Hermida Merino, ${ }^{\ddagger}$ and Natalie Malikova ${ }^{*} \dagger$ \\ Sorbonne Université, CNRS, Laboratory of Physical Chemistry of Electrolytes and \\ Interfacial Nanosystems (PHENIX), 75005 Paris, France, and ESRF, The European \\ Synchrotron, 71 Avenue des Martyrs, 38000 Grenoble France \\ E-mail: natalie.malikova@sorbonne-universite.fr
}

\begin{abstract}
We study the aggregation of charged plate-like colloids, Na-montmorillonite clays, in the presence of ionenes, oppositely charged polymer chains. The choice of the charged polymer allows tuning its linear charge density to match/mismatch the average charge separation on the clay surfaces. We assess the nanoscale structure of the aggregates formed by small angle X-ray and neutron scattering (SAXS, SANS). The nanoscale features of the formed clay aggregates are dominated by the presence of a stacking peak, giving clear evidence for the formation of clay tactoids, i.e. a face-to-face aggregation geometry of the clay platelets. The chain charge density of ionenes influences the stacking repeat distance within the clay tactoids, but also the extent of stacking
\end{abstract}

\footnotetext{
*To whom correspondence should be addressed †PHENIX

${ }^{\ddagger} \mathrm{ESRF}$
} 
and abundance of the tactoids. We may distinguish two regimes as a function of clay and ionene polymer charge densities ( $\rho_{c}$ and $\rho_{p}$ respectively). The first regime applies to $\rho_{p}>\rho_{c}$ and $\rho_{p} \sim \rho_{c}$, i.e. for highly and "matching" charged chains. Under these conditions the intercalated chains lie in a flat conformation within the tactoids, irrespective of the ionic strength (within the range studied, i.e. up to $0.05 \mathrm{M} \mathrm{NaBr}$ ). For weakly charged chains, $\rho_{p}<\rho_{c}$, undulation of the ionene chains within the tactoid is seen. The degree of undulation increases with ionic strength, due to the decreasing persistence length of the ionene chains. The extent of stacking (5-10 platelets per tactoid) is a general feature of all the systems and its origin remains unknown. The system corresponding to the closest match in charge separations on the clay surface and on the polymer chain $\left(\rho_{p} \sim \rho_{c}\right)$ features the highest abundance of tactoids. This coincides with the highest macroscopic density as deduced from simple visual inspection of sediment volumes. This leads to the open question regarding the link between the density at the nanoscale and the macroscopic density and sedimentation behaviour of the aggregate.

\section{Introduction}

Numerous environmental and industrial technologies, such as the purification of waste water, paper making and civil engineering have to handle large amounts of colloidal dispersions and ultimately reach a separation of the solid and liquid component. Aggregation or flocculation of the colloidal particles, followed by their sedimentation, is the major pathway to achieve this. Clay minerals, the subject of the present study, occupy an important place among the colloids to process. As constituents of soil, clay aggregation is particularly relevant in the treatment of slurries from civil engineering and mineral processing. ${ }^{1}$

From a fundamental point of view, the particularity of clay colloids is their highly anisotropic, plate-like shape. While aggregation is mostly studied on spherical colloids, anisotropy leads to a much richer set of possible aggregation geometries. ${ }^{1,2}$ For clay suspensions flocculated by simple electrolytes (inorganic salts), some experimental studies highlight 
the house-of-cards model (face-to-edge geometry), ${ }^{3}$ while others give strong evidence for the plate stacking (face-to-face geometry). ${ }^{4}$ The latter geometry has been reported for other plate-like colloids, such as boehmite nano platelets. ${ }^{5}$ Needless to say, the prevailing geometry influences drastically the local aggregate density.

The key to the flocculation process is the nature of the destabilising agent, which needs to be efficient and meet several requirements, which are both economic and environmental. The current emphasis on green technologies sees an increasing number studies on eco-friendly flocculants, in form of bio-inspired polymers, such as chitosan, starch derivatives and other glycopolymers, e.g. ${ }^{6}$ For the frequent case of charged colloids, such as certain types of clays, the use of charged polymers (polyelectrolytes) turns out to be significantly more efficient than the addition of simple electrolytes (inorganic salts). ${ }^{7,8}$ Beyond electrostatic screening, the conformation of the charged polymer chains on the colloidal surface dictates the aggregation mechanism, of which we distinguish three main pathways 1) polymer chain bridging, 2) polymer chain patching, and 3) depletion aggregation involving the free, desorbed polymer chains in the suspension. ${ }^{7,9-13}$ In most cases, several of these mechanisms takes place simultaneously.

In polyelectrolyte-induced aggregation, a set of key parameters influences the amount and conformation of the adsorbed polymer on the colloidal surface, as well as the overall charge and structure of the aggregate. These parameters include the salt concentration, polyelectrolyte chain flexibility, linear charge density and surface curvature of the colloid or macroion. ${ }^{11,12,14}$ They have been investigated mainly for spherical colloids, ${ }^{15-20}$ though planar colloidal geometries, of particular relevance to clays, have also been explored. ${ }^{15,21,22}$ The conformation of charged chains confined between oppositely charged plates has been investigated by Monte Carlo simulations and field theory including ion-ion correlations, highlighting the effect of chain stiffness on the polymer bridging between the two surfaces. ${ }^{23,24}$ Moving from flexible polymers to rigid rods, the bridging capacity of the polymers is at first extended to larger distances but then is lost in favour of a thin adsorbed layer of the rigid rods on the 
surfaces, yielding very short range attractions. This limit of a thin adsorbed layer shall be particularly relevant to the data discussed here.

In the current manuscript we concentrate on the parameter of polyelectrolyte chain charge density relative to the surface charge density of the colloid. We call upon a well-defined model experimental system: clay colloids of specific size fractions resulting from purification and size fractionation of natural Wyoming montmorillonite ${ }^{25,26}$ and ionene charged polymer chains. ${ }^{27-29}$ Ionenes can be considered as model cationic polymer chains due to their simple chemical structure, which is free of bulky side groups, and their regular (not statistical) and tuneable charge density along the chains: quaternary ammonium centers as part of the main hydrocarbon chain, separated by a pre-defined number of methylene $\left(\mathrm{CH}_{2}\right)$ spacer units. ${ }^{27,29}$ As a consequence, and contrary to the majority of polyelectrolyte chains, the linear charge density of ionenes can indeed be tuned to match/mismatch the average charge separation on the clay surfaces. For the structure and nomenclature of ionenes, see Figure 1. Ionenes have already been studied in connection with several applications, including ion-exchange resins, ${ }^{30}$ humidity detectors, ${ }^{31}$ organic templates in the synthesis of mesoporous silica, ${ }^{32}$ and as antimicrobial agents. ${ }^{33,34}$ Besides the process of aggregation in clay suspensions, studying the interaction of model organic chains with clay mineral surfaces is of direct relevance for the understanding of the retention/release of organic contaminants in soil. ${ }^{35}$

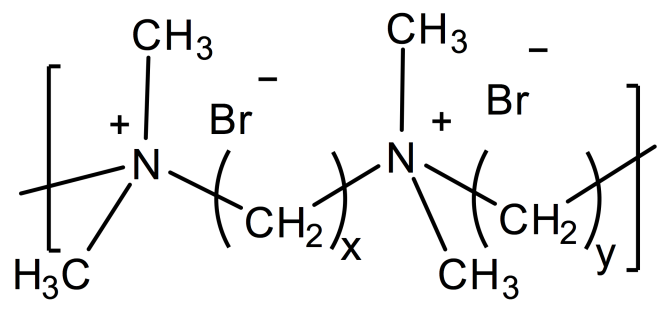

Figure 1: Structure of an x,y-ionene polymer: charged ammonium quaternary centers on the main backbone are separated by $\mathrm{x}$ or $\mathrm{y}$ methylene groups in an alternating manner. Charge is compensated by $\mathrm{Br}^{-}$ions.

We have recently investigated the aggregation of clay platelets in the presence of ionene polymers, using a combination of light absorbance (turbidity) and $\zeta$-potential measure- 


\section{Experimental Section}

\section{Materials}

Ionenes and theirs precursors were synthesized using a procedure adapted from those described previously. ${ }^{29,39}$

Preparation of dimethylamine (DMA) aqueous solution. Dimethylamine hydrochloride ( $86.0 \mathrm{~g}$, 
$1.05 \mathrm{~mol}$ ) was transferred in to a two-necked, 500mL round-bottom flask equipped with a magnetic stirrer. One neck was connected to a dropping funnel containing $\mathrm{NaOH}$ aqueous solution at $23 \mathrm{M}(50 \mathrm{~mL},, 1.15 \mathrm{~mol})$ and the other one to the tube immersed in ice-cold water $(18 \mathrm{~mL}) . \mathrm{NaOH}$ solution was added dropwise to dimethylamine hydrochloride (DMA.HCl) while stirring at $10{ }^{\circ} \mathrm{C}$. The mixture was warmed to its initial boiling point $\left(55^{\circ} \mathrm{C}\right)$ and then slowly further on up to $90{ }^{\circ} \mathrm{C}$. Vapours of DMA were condensed/dissolved while passing through the ice-cold water. The procedure yielded an aqueous solution $(57 \%, 51.7 \mathrm{~g}$, $0.63 \mathrm{~mol}$ ) of DMA.

Synthesis of $N, N, N^{\prime}, N^{\prime}$-tetramethyl-1,12-dodecanediamine. 1,12-Dibromododecane (8.35 g, $25 \mathrm{mmol}$ ) was dissolved in tetrahydrofuran $(70 \mathrm{~mL})$ into a $250 \mathrm{~mL}$ round-bottom flask. The solution was cooled to $-78{ }^{\circ} \mathrm{C}$ and an aqueous solution of DMA (57\%, $\left.39.5 \mathrm{~g}, 0.5 \mathrm{~mol}\right)$ was added. After being stirred for $30 \mathrm{~min}$ at the same temperature, the reaction mixture was allowed to warm to room temperature and stirred for $24 \mathrm{~h}$. Volatile components were removed under reduced pressure, and the resulting white residue was dissolved in $2 \mathrm{M} \mathrm{NaOH}$ aqueous solution $(200 \mathrm{~mL})$. Thereafter the liquid phase was extracted with diethyl ether several times. The combined organic layers were collected and concentrated to obtain a yellow oil. The crude product was puri?ed via vacuum distillation $\left(100{ }^{\circ} \mathrm{C}\right.$ and $\left.1 \mathrm{mbar}\right)$ from $\mathrm{CaH}_{2}$ to provide a clear colourless liquid product $(4.5 \mathrm{~g}, 90 \%$ yield).

Synthesis of 12,12-Ionene Bromide. N,N,N',N'-tetramethyl-1,12-dodecanediamine (4.5 g, $22.5 \mathrm{mmol})$ was added to a solution of 1,12-Dibromododecane (5.77 g, $22.5 \mathrm{mmol})$ in methanol $(55 \mathrm{~mL})$. The reaction mixture was stirred for 3 days at $45^{\circ} \mathrm{C}$. The solution was then concentrated and the residue was precipitated with diethylether. After the decantation, the supernatant was eliminated. The solid was dissolved in water and washed with diethylether. After elimination of water by freeze-drying, the 12,12-ionene was obtained as white solid $(12,49 \mathrm{~g}, 95 \%)$.

Synthesis of 6,6-, and 3,3-Ionene Bromides. These ionenes were prepared as described for 12,12-ionene bromide, with the appropriate dibromoalkanes and diaminoalkanes. ${ }^{28,29,40}$ In the 
case of 3,3-ionene bromide, small amounts of water were repeatedly added into the reaction mixture, when it became white and very viscous, to ensure the solubility of all components.

Molecular weight of ionenes were determined by size exclusion chromatography (SEC) as described in ref. ${ }^{36}$ The analysis yielded $\mathrm{Mn}=39500 \mathrm{~g} / \mathrm{mol}$ and $\mathrm{Mw}=48500 \mathrm{~g} / \mathrm{mol}$, thus a polydispersity index of 1.23. Expressed in terms of $\mathrm{Mn}+/-$ one standard deviation, this leads to a range of molecular weights of 20000 - $60000 \mathrm{~g} / \mathrm{mol}$. This in turn corresponds to $100-300 \mathrm{~nm}$ in terms of chain length. SEC measurements on cationic polyelectrolytes are very difficult ${ }^{41}$ and, for us, were successful only for 6,9-ionenes. In the following we consider that the above range of molecular weights applies also to ionenes of other charge densities, which were synthesized under identical conditions. We have indeed confirmation that the molecular weights of different ionenes are of the same order of magnitude, from the NMR signal of amine end groups, which allow estimation of the degree of ionene polymerisation. ${ }^{42}$

The aluminosilicate clay colloid used was Na-montmorillonite from Wyoming with a cation exchange capacity (CEC) of $96 \mathrm{mmol} / 100 \mathrm{~g}$. Wyoming montmorillonite was purchased from the Source Clays Repository at Purdue University, Indiana. Clay suspension was purified and separated in size by centrifugation under different gravitational fields to obtain fractions with narrow platelet size distributions. ${ }^{25,26,36}$ Here we used two size fractions of montmorillonite platelets: average lateral dimension of $490 \mathrm{~nm}$ and $240 \mathrm{~nm}$ (size fractions denoted $\mathrm{T} 1$ and $\mathrm{T} 2$ respectively). The size and charge density characteristics of ionene polymers and clays used are summarized in Table 1.

\section{Methods}

Preparation of flocculated clay-ionene aggregates. Flocculated clay-ionene aggregates were prepared in $15 \mathrm{~mL}$ conical tubes. Starting with a clay suspension in deionized water $(<10 \mathrm{~mL})$, a small varying volume of aqueous ionene solution $(20 \mathrm{~g} / \mathrm{L}, 5-100 \mu \mathrm{L})$ was added. In this manner we achieved varying the ratio of $c^{+} / c^{-}$in the final mixture (the ratio between positive charges on the polymer chains and negative charges on the clay particles), 
while keeping to a constant clay concentration across the series. Different series were prepared, corresponding to $2,5,8$ and $27 \mathrm{~g} / \mathrm{L}$ in final clay concentration. Note that the $c^{+} / c^{-}$ ratio can be calculated from the ionene monomer concentration, clay concentration and the corresponding CEC of the clay (here $96 \mathrm{mmol} / 100 \mathrm{~g}$ ). In view of the significant basal charge on the clay used, the edge (lateral) charges were neglected in the calculation. After the addition of ionene solution into the clay suspension, the mixture was stirred manually for 20 seconds and then left to settle for 30 minutes. The clay-ionene aggregates in the bottom part of the tube were later used in scattering experiments.

Small angle X-ray scattering experiments ( $S A X S)$ ). SAXS experiments were performed at the Dutch Belgian beamline BM26B (Dubble) of the ESRF (Grenoble, France) using an incident energy of $12 \mathrm{keV}$ (i.e. wavelength of $1 \AA$ ), with a sample-to-detector distance of $1 \mathrm{~m}$ and 3 m. The $\mathrm{q}$ range thus available was $8 \times 10^{-2} \mathrm{~nm}^{-1}<\mathrm{q}<5.6 \mathrm{~nm}^{-1}$, where $\mathrm{q}$ is the wave vector $\left(q=\frac{4 \pi \sin \theta}{\lambda}\right.$, with $2 \theta$ being the scattering angle and $\lambda$ the wavelength). Flocculated clay-ionene aggregates were conditioned in cylindrical cells of $0.8 \mathrm{~mm}$ in thickness, with thin mica windows. Two-dimensional images were obtained on a Pilatus detector. Radial integration of the data provided $I(q)$ curves that were corrected for the signal of the solvent and the empty cell. The final curves are plotted in absolute intensity $\left(\mathrm{cm}^{-1}\right)$ after calibration using a glassy carbon standard.

Small angle neutron scattering $(S A N S)$. SANS experiments were performed at Laboratoire Léon Brillouin (LLB), CEA Saclay (France) on the PACE spectrometer, using a neutron beam with a wavelength of $4.6 \AA$ and a sample-to-detector distance of $1 \mathrm{~m}$ and $3 \mathrm{~m}$. The available q range was thus $1.43 \times 10^{-1}$ to $4.81 \mathrm{~nm}^{-1}$. SANS measurements were carried out on clay-ionene aggregates formed from an initial clay concentration of $27 \mathrm{~g} / \mathrm{L}$. Lower initial clay content yielded insufficient SANS intensity. The measurements were performed under the contrast matching condition for the clay particles, which is achieved with a $\mathrm{H}_{2} \mathrm{O}$ and $\mathrm{D}_{2} \mathrm{O}(35 \% / 65 \%)$ solvent mixture. ${ }^{43}$ 
Table 1: Summary of size and charge-density characteristics for ionene polymers and clay colloids used in this study.

\begin{tabular}{|c|c|c|c|c|}
\hline Polymer & $\begin{array}{l}\text { Molecular Weight } \\
(\mathrm{g} / \mathrm{mol})\end{array}$ & $\begin{array}{l}\text { Chain Length } \\
\text { (nm) }\end{array}$ & $\begin{array}{l}\text { Number of } \mathrm{N}+ \\
\text { centres per chain }\end{array}$ & $\begin{array}{c}\text { charge separation } \\
(\AA)\end{array}$ \\
\hline 3,3-ionene & \multirow{3}{*}{$20000-60000$} & \multirow{3}{*}{$100-300$} & $200-600$ & 5.00 \\
\hline 6,6-ionene & & & $110-340$ & 8.75 \\
\hline 12,12 -ionene & & & $60-190$ & 16.25 \\
\hline
\end{tabular}

\begin{tabular}{|c|c|c|c|}
\hline Montmorillonite & Lateral size $(\mathrm{nm})$ & CEC $(\mathrm{mmol} / 100 \mathrm{~g})$ & charge separation $(\AA)$ \\
\hline \hline T1 & 490 & & \\
\hline T2 & 240 & 96 & $\sim 8$ \\
\hline
\end{tabular}

\section{Results and Discussion}

Let us consider at first a reference, the SAXS signal from a pristine (unflocculated) suspension of clay platelets, represented by the full black curve in Figure 2, where radially integrated scattered intensity $I(q)$ is plotted versus the wave-vector $q$. This reference curve features a decay of the scattered signal very close to $\mathrm{a}^{-2}$ law (dashed straight line in Figure 2) across the entire $q$ range studied, which is typical for the scattering from flat surfaces. ${ }^{44}$ Considering the size of the scattering objects, here colloidal platelets with a thickness of $1 \mathrm{~nm}$ and an average lateral dimension of $490 \mathrm{~nm}$ (T1 montmorillonite clay), we would indeed expect the $\mathrm{q}^{-2}$ law for wave-vectors above $2 \pi / 490=0.013 \mathrm{~nm}^{-1}$, i.e. in the entire q-range studied and shown in Figure 2. Any variations in the scattered signal in the q-range of Figure 2 inform us on structural features within distances smaller than the lateral dimensions of the colloidal platelets. It shall give access to the local organisation of the platelets. An alternative, $q^{2} I(q)$, representation of the same data is given in Figure 3, where the reference curve now becomes a constant (black curve) and additional features due to local structuring shall be easily discernable. 


\section{Effect of polymer chain charge density on local aggregate structure}

SAXS signals of clay-ionene aggregates are featured in Figure 2 and 3, alongside the reference curve, for a series of aggregates with varying chain charge density of the ionene polymer. For each chain charge density, the system was prepared at the condition of optimal aggregation, as defined previously. This optimum corresponds to $c^{+} / c^{-}$between 0.3 and 0.5 (the optimum occurs at slightly higher $c^{+} / c^{-}$ratios, as the chain charge density decreases). Two important changes with respect to the reference curve are evident: (a) a broad correlation peak is very prominent in the scattered signal from all three flocculated systems and its position, width and intensity varies with the polymer chain charge density, (b) the scattered signal from the flocculated suspensions looses the $\mathrm{q}^{-2}$ decay across the $\mathrm{q}$ range probed, the decay exponent is now between -2.5 to -2.7 (determined between 0.08 and $0.5 \mathrm{~nm}^{-1}$ ), so higher in absolute value than for the pristine clay suspension.

Let us concentrate now on the broad correlation peak in the SAXS spectra, conveniently visible in the $q^{2} I(q)$ representation of Figure 3. Its position, its width as well as its intensity contain information on the local structure of the clay-ionene aggregates. The peak appears due to the formation of clay tactoids, in which the clay platelets stack in a face-to-face manner. Tactoids are known to be formed in clay suspensions in the presence of multivalent inorganic ions, ${ }^{4,45}$ here we show them clearly in the presence of charged polymer chains. The position of the peak maximum reflects the repeat or interlamellar distance within the tactoid according to $d=2 \pi / q_{\max }$. The significant width of the correlation peak indicates that the regular stacking does not extend over many platelets. In other words, clay tactoids are only the building blocks of the overall aggregate, which is disordered on larger scales. No further correlation peaks are visible in the spectra at lower wave-vectors and the overall aggregate can only be characterised by the decay exponent of the scattered intensity $(-2.5$ to -2.7$)$, which reflects in broad terms its density.

The Full-Width at Half-Maximum (FWHM) of the broad correlation peak at high $q$ can be used to estimate the number of the platelets within the tactoid $(N)$. The Scherrer formula 


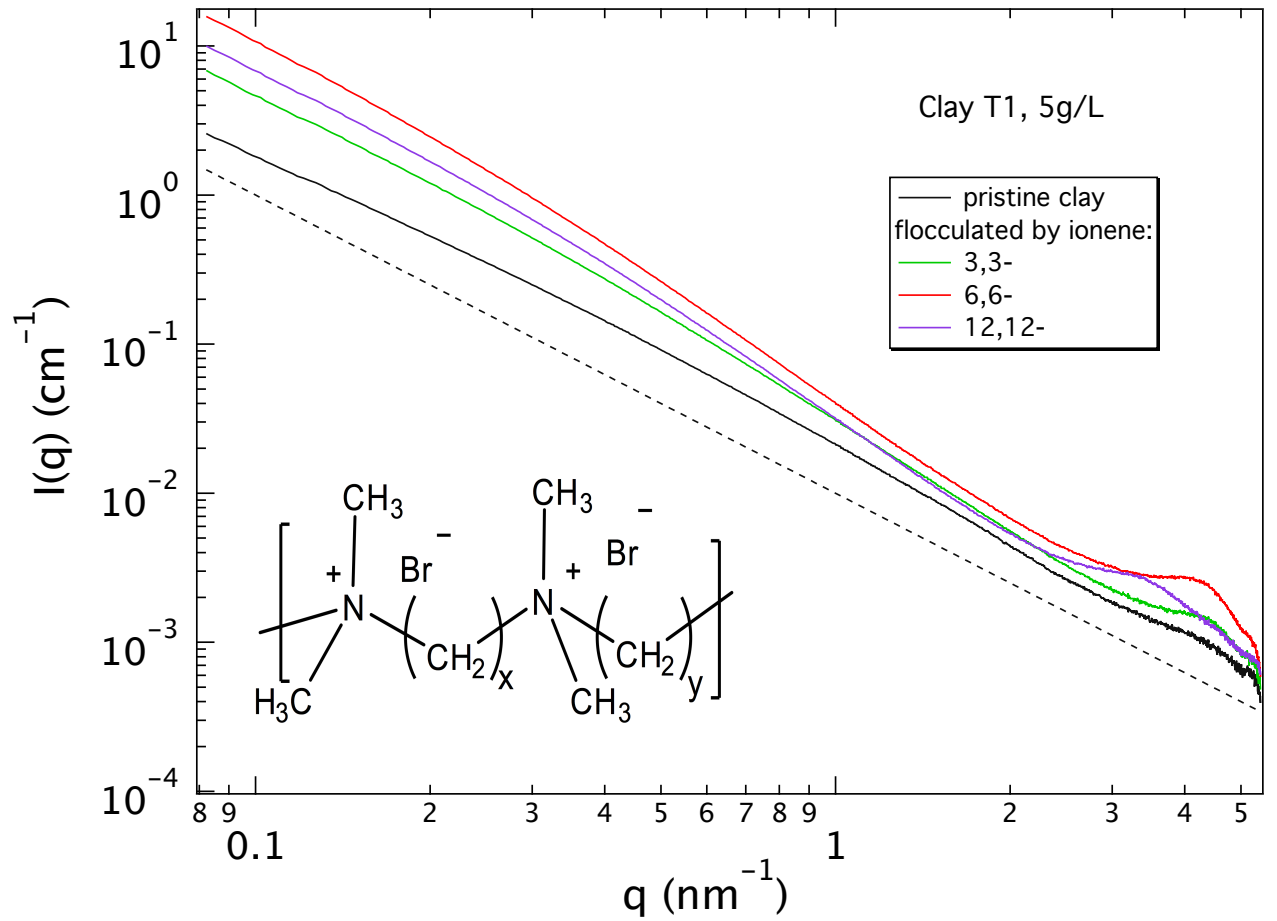

Figure 2: Small angle X-ray scattering (SAXS) intensity versus the wave-vector q for a pristine clay suspension (black) and a series of clay-ionene aggregates (T1 montmorillonite clay platelets, lateral dimension of $490 \mathrm{~nm}$, initial clay concentration of $5 \mathrm{~g} / \mathrm{L}$ ) for $\mathrm{x}, \mathrm{y}$-ionene polymers of the type : $\mathrm{x}, \mathrm{y}=3,3 ; 6,6$ and 12,12 (ordered from highest to lowest chain charge density, see insert for $\mathrm{x}, \mathrm{y}$-ionene structure), at the point of optimal aggregation. A guide to the eye corresponding to a $\mathrm{q}^{-2}$ dependence (typical signal from flat surfaces) is shown as a dashed line. 


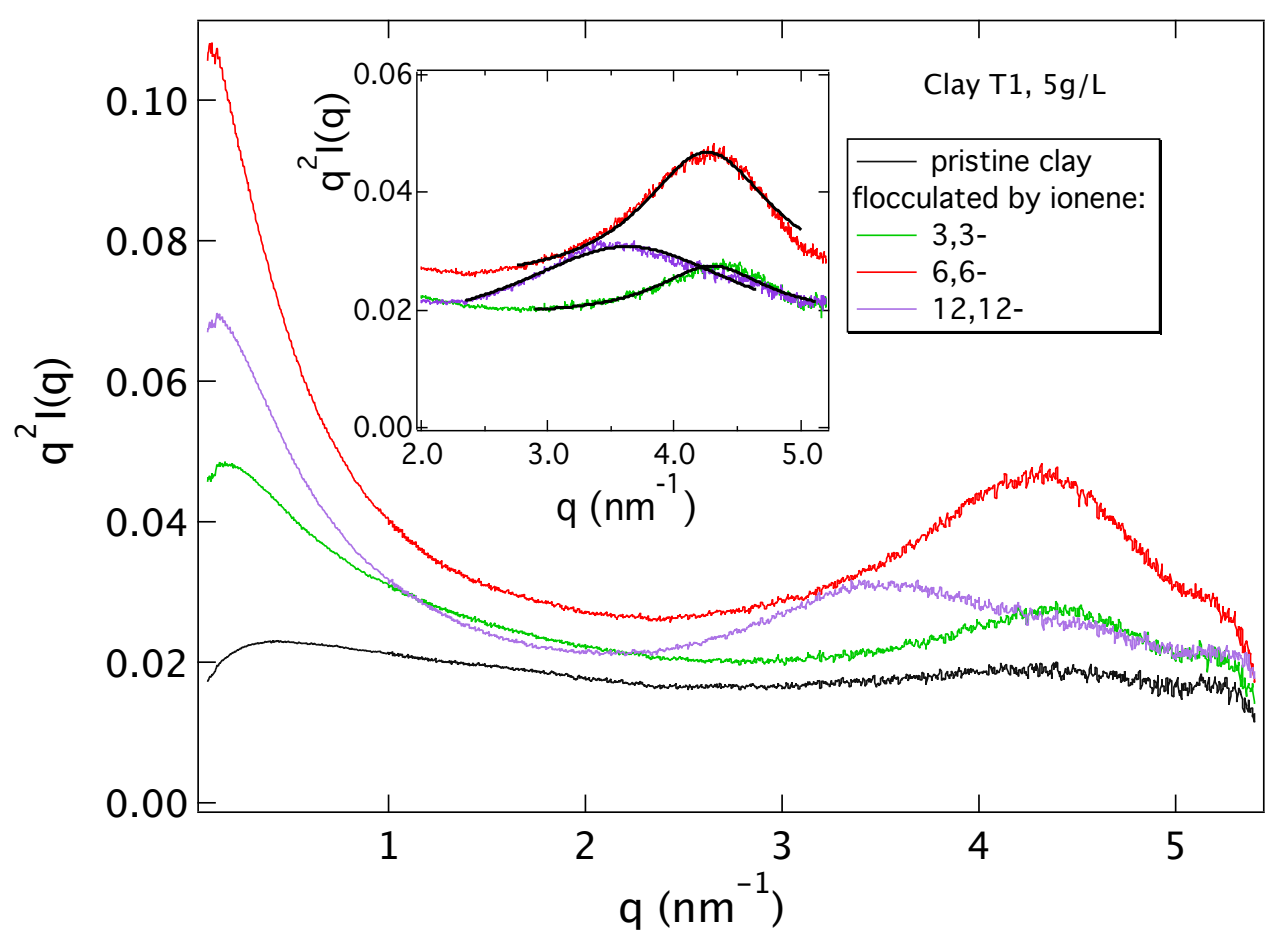

Figure 3: The same data sets as in Figure 2, now in the $q^{2} I(q)$ representation, to highlight any correlation peaks in the high $q$ region. The insert features a zoom on the correlation peaks and the associated Lorentzian fits. 
While the clay aggregates flocculated by $3,3-$ and 6,6 -ionene feature a very similar interlammellar distance of $1.43-1.46 \mathrm{~nm}(14.3-14.6 \AA)$, in the case of 12,12-ionene this distance increases by $0.4 \mathrm{~nm}(4 \AA)$. These distances can be put into the context by considering the thickness of a single clay layer and the cross-section of an ionene chain. The former is $6.54 \AA^{25,49,50}$ while the cross-section of an ionene chain can be estimated as $5 \AA$. This is the diameter of a tetramethylammonium ion, very close in structure to the charged centres on the ionene chains. ${ }^{51}$ Let us start by considering a single layer of ionene chains intercalating the clay platelets and laying flat between the adjacent clay surfaces, which would yield a spacing of $11.5 \AA$. The flat configuration is indeed to be expected for the 3,3- and 6,6-ionenes, due to the charge separation on the chains being smaller or indeed matching, for 6,6-ionene, the average charge separation on the clay surfaces. The observed interlammellar spacing of the 
clay aggregates formed by 3,3- and 6,6-ionenes (14.3-14.6 $\AA$ ) is greater than this theoretical value but only by $3 \AA$. This is not sufficient to evoke a double layer of intercalated ionene chains. For all aggregates we bear in mind that they are ionene-deficient, i.e. $c^{+} / c^{-}$is less than 1 (refer to Table 2 for details). Thus the intercalated ionene chains do not compensate all the charge of the clay particles and additional $\mathrm{Na}^{+}$ions must be part of the aggregate, almost certainly in a hydrated form. Even hydration of the charges on the ionene chains cannot be excluded. For the aggregates formed by 12,12-ionenes the vertical space available for the chains between adjacent clay platelets almost $12 \AA$, thus approximately double the ionene chain cross-section. However, rather than a double layer of ionene chains, we expect a degree of undulation of the 12,12-ionene chains, as would be expected for a situation where the charge separation on the chains is larger than the average charge separation on the clay surface (refer back to Table 1). A double layer of 12,12-ionene chains in the tactoid is also incompatible with the ionene content, as reflected by the $c^{+} / c^{-}$parameter, which is only slightly higher for 12,12- in comparison to 3,3- and 6,6-ionenes (refer back to Table 2).

The width and the intensity of the correlation peak in Figure 3 inform us, respectively, on the extent of stacking within individual tactoids and on the tactoid abundance within the overall aggregates. Table 2 shows that the high and medium charged ionenes $(3,3-$ and 6,6-) lead to a somewhat larger value of platelets $(N)$ within the tactoid, in comparison to the weakly charged chains $(12,12$-ionenes). In view of the above-mentioned undulation of the intercalated weakly charged chains, this is not surprising, as the stacking is likely to be of a lower quality in such a case. Further, we note a significantly higher intensity of the stacking peak for the aggregates containing 6,6-ionenes. These chains are particular (refer back to Table 1) in that their charge separation matches the closest that of the clay surface. We suggest that this match favours the formation of tactoids and thus leads to a more prominent correlation peak. At the same time, the stacking does not persist across a larger domain, the width of the peak is comparable to the case of 3,3-ionenes. 


\section{Tactoid structure as a function of clay and ionene concentrations}

We have investigated the effect of scaling up both the clay and the ionene concentrations in the flocculating system on the structure of the tactoids formed. This is done at a constant $c^{+} / c^{-}$ratio, corresponding to the optimum of flocculation. The SAXS results for clay mixtures with 3,3-; 6,6- and 12,12-ionenes are shown in Figure 4. Firstly, the results reveal tactoid formation for all concentrations, with the average number of platelets within tactoids increasing with initial clay concentration (reflected in the FWHM of the stacking peak). Secondly, the stacking repeat distance within the tactoids is independent of clay concentration for 3,3- and 6,6-ionenes. On the contrary, for the case of 12,12-ionenes we see a gradual shift of the stacking peak towards lower wave-vectors, thus higher distances: stacking repeat distance changes from $1.69 \mathrm{~nm}$ at $2 \mathrm{~g} / \mathrm{L}$ to $1.89 \mathrm{~nm}$ at $27 \mathrm{~g} / \mathrm{L}$. In light of the previously mentioned undulation of the 12,12-ionene chains within the tactoids, these data suggest increasing undulation as we concentrate the clay-ionene system (and thus increase the ionic strength). We shall return to this point in a later section, our interpretation is related to the decreasing persistence length of the 12,12-ionene chains, as the system is concentrated.

\section{SANS signal from polymer chains within tactoids}

Having proposed that ionene chain density governs the means of intercalation inside the clay tactoids, we turned towards small angle neutron scattering (SANS) measurements under the contrast matching condition, ${ }^{44}$ to provide information on the conformation of ionenes directly inside the clay ionene tactoids. An exploitable SANS signal was only obtained for initial clay concentration of $27 \mathrm{~g} / \mathrm{L}$ ( or $1 \%$ in volume fraction), thus approximately 5 times more concentrated than the majority of the SAXS measurements presented here $(5 \mathrm{~g} / \mathrm{L}$ or $0.19 \%$ in volume fraction). The results in the previous section, concerned with tactoid structure as a function of clay and ionene concentrations at a constant $c^{+} / c^{-}$ratio, was thus a necessary pre-requisite.

The possibility to match the scattering length density of clay particles in an aqueous 

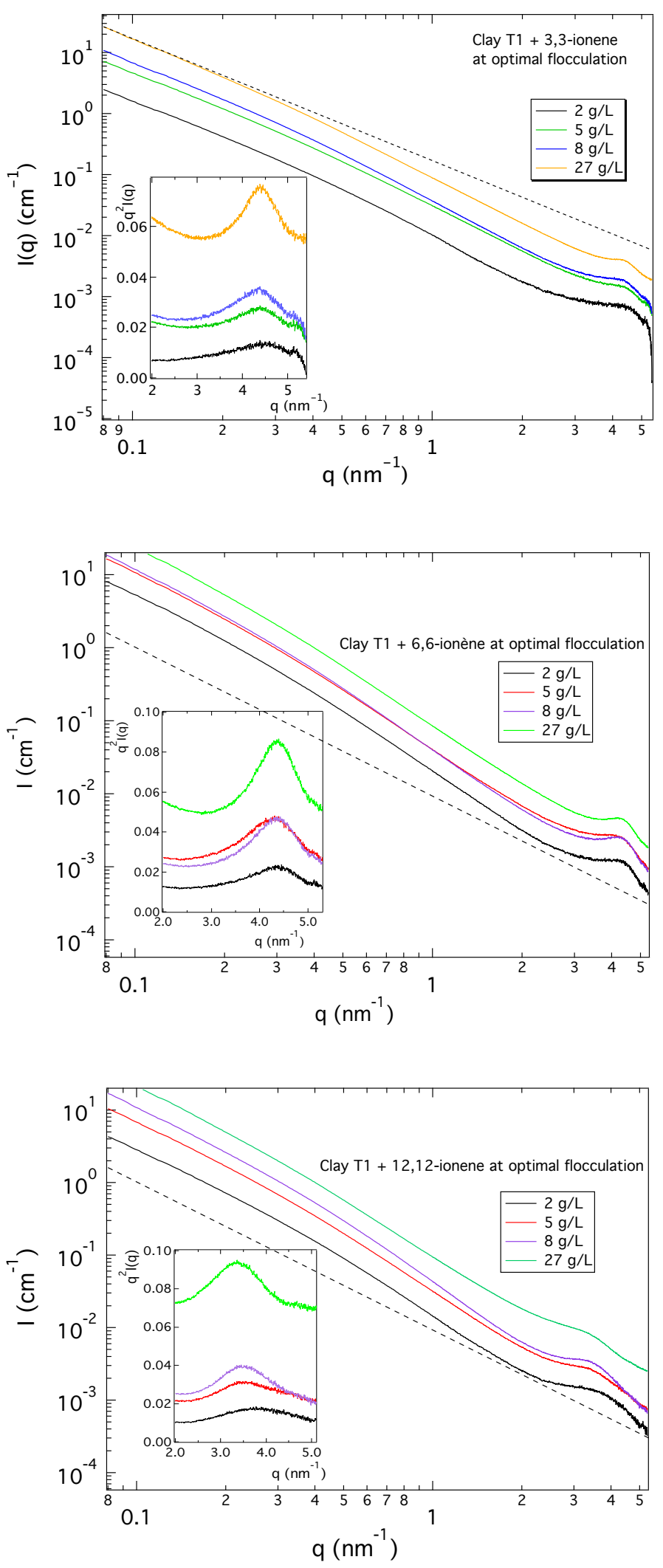

Figure 4: Small angle X-ray scattering (SAXS) intensity versus the wave-vector q for a series of suspensions of montmorillonite T1 clay particles, of varying initial clay concentration, aggregated by 3,3-ionene (top), 6,6-ionene (1Genter) and 12,12-ionene (bottom). All data

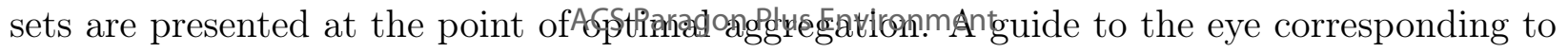
a $\mathrm{q}^{-2}$ dependence is shown as a dashed line. 


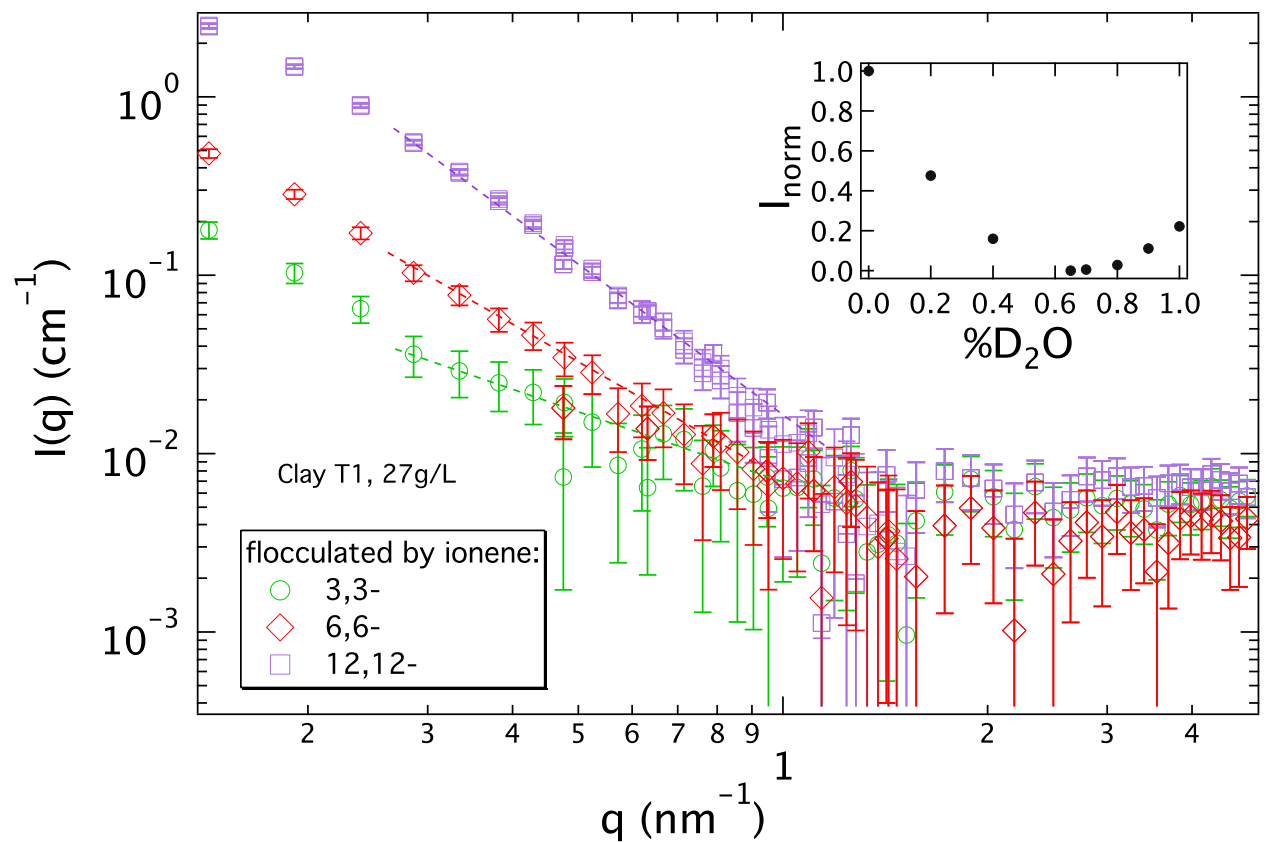

Figure 5: SANS intensity versus the wave-vector $\mathrm{q}$ for a series of montmorillonite clay suspensions (initial clay concentration of $27 \mathrm{~g} / \mathrm{L}$, clay discs of $490 \mathrm{~nm}$ in lateral dimension on average) aggregated by ionene chains of the type : 3,3-; 6,6- and 12,12- (ordered from highest to lowest chain charge density). The solvent composition is $35 \% / 65 \% \mathrm{H}_{2} \mathrm{O} / \mathrm{D}_{2} \mathrm{O}$ and its scattering length density matches that of the montmorillonite colloids, thus only the signal from the ionene chains in the aggregates is measured. Insert: Normalised integrated coherent SANS intensity (integrated over the accessible q range) versus solvent composition (percentage of $\mathrm{D}_{2} \mathrm{O}$ in a mix of $\mathrm{H}_{2} \mathrm{O} / \mathrm{D}_{2} \mathrm{O}$ ) for a pristine suspension of Na-montmorillonite at $27 \mathrm{~g} / \mathrm{L}$, corresponding to $1 \%$ in volume fraction. 
suspension, by a combination of $\mathrm{H}_{2} \mathrm{O}$ and $\mathrm{D}_{2} \mathrm{O}$ has been demonstrated on a suspension of laponite (a synthetic clay), using a solvent with a $35 \% / 65 \% \mathrm{H}_{2} \mathrm{O} / \mathrm{D}_{2} \mathrm{O}$ composition. ${ }^{43}$ Our measurements have shown that the same composition can be used to match the signal of Na-montmorillonite, as is shown in the insert of Figure 5. The SANS intensity presented in the main graph of Figure 5 has been corrected for a constant incoherent background, arising from hydrogen atoms in the solvent but also from the ionene chains. In the case of ioneneclay aggregates, this subtraction can only be done approximatively, as we do not possess the exact value for the density of the aggregates and the ionene chains therein. Also, the contrast conditions of our systems lead to measuring both the intra-chain and inter-chain correlations, thus conclusions on the individual chain conformations are necessarily based on neglecting the inter-chain contribution to the scattered signal, in the $q$ region considered. Therefore we restrict ourselves here to commenting only in general terms on the trends observed. The corrected SANS data are characterised by a power-law decrease below $q=0.1 \AA^{-1}$, followed by a constant background. The decay exponent for the first part of the SANS curves increases as we move from strongly to weakly charged chains forming the aggregate. This indicates an increasing flexibility of the polymer chains inside the tactoids, in line with the interpretation of the SAXS spectra.

\section{Effect of polymer - clay stoichiometry, the $c^{+} / c^{-}$ratio}

We have shown previously that the ionene-clay system allows us to trace the formation of aggregates at precise ratios of $c^{+} / c^{-} .{ }^{36}$ As mentioned above, the point of optimal aggregation $\left(c^{+} / c^{-}\right)_{o p t}$ is dependent on the ionene chain charge density and tends to occur for higher $c^{+} / c^{-}$as the chain charge density decreases. For a given system, SAXS data as a function $c^{+} / c^{-}$allows to trace the emerging structure of the aggregates, as we approach the point of optimal aggregation and further on. Figures 6 and 7 present such sequences for the most highly and weakly charged ionene chains. Clearly, in both cases, a stacking peak is present at the point of optimal aggregation and for all higher values of $c^{+} / c^{-}$. Beyond $\left(c^{+} / c^{-}\right)_{o p t}$, 

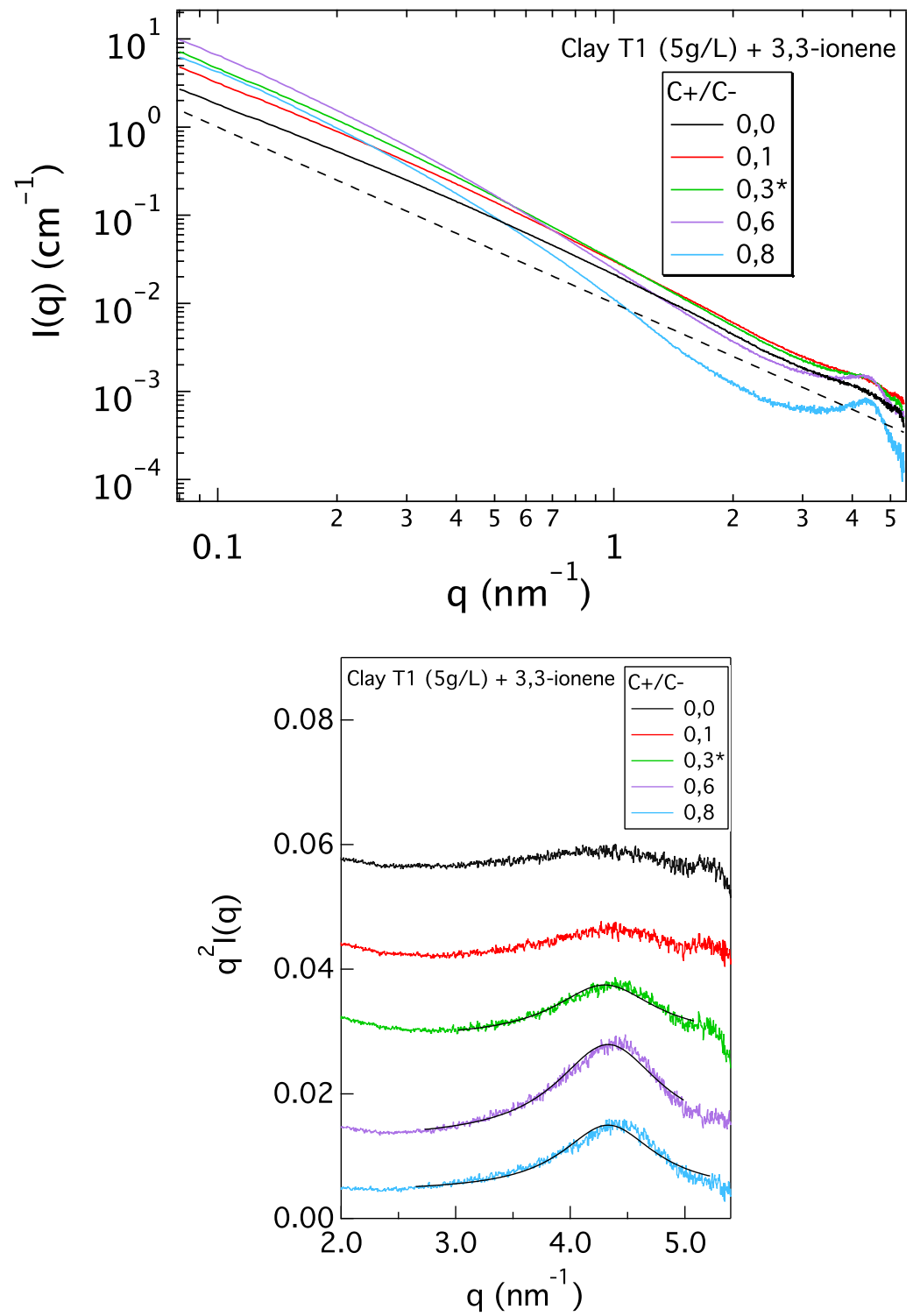

Figure 6: SAXS intensity versus the wave-vector q for a series of suspensions of montmorillonite T1 clay particles (initial clay concentration of $5 \mathrm{~g} / \mathrm{L}$ ) aggregated by 3,3-ionene chains, at different ratios of $c^{+} / c^{-}$. The point of optimal aggregation $\left(c^{+} / c^{-}=0.3\right)$ is denoted by an asterisk. (top) $I(q)$ representation, where a guide to the eye corresponding to a $\mathrm{q}^{-2}$ dependence is shown as a dashed line and (bottom) $q^{2} I(q)$ representation, where the consecutive curves have been shifted along the y-scale for clarity. Lorentzian fits of the correlation peak at high $q$ are shown for the last three curves in the series. 

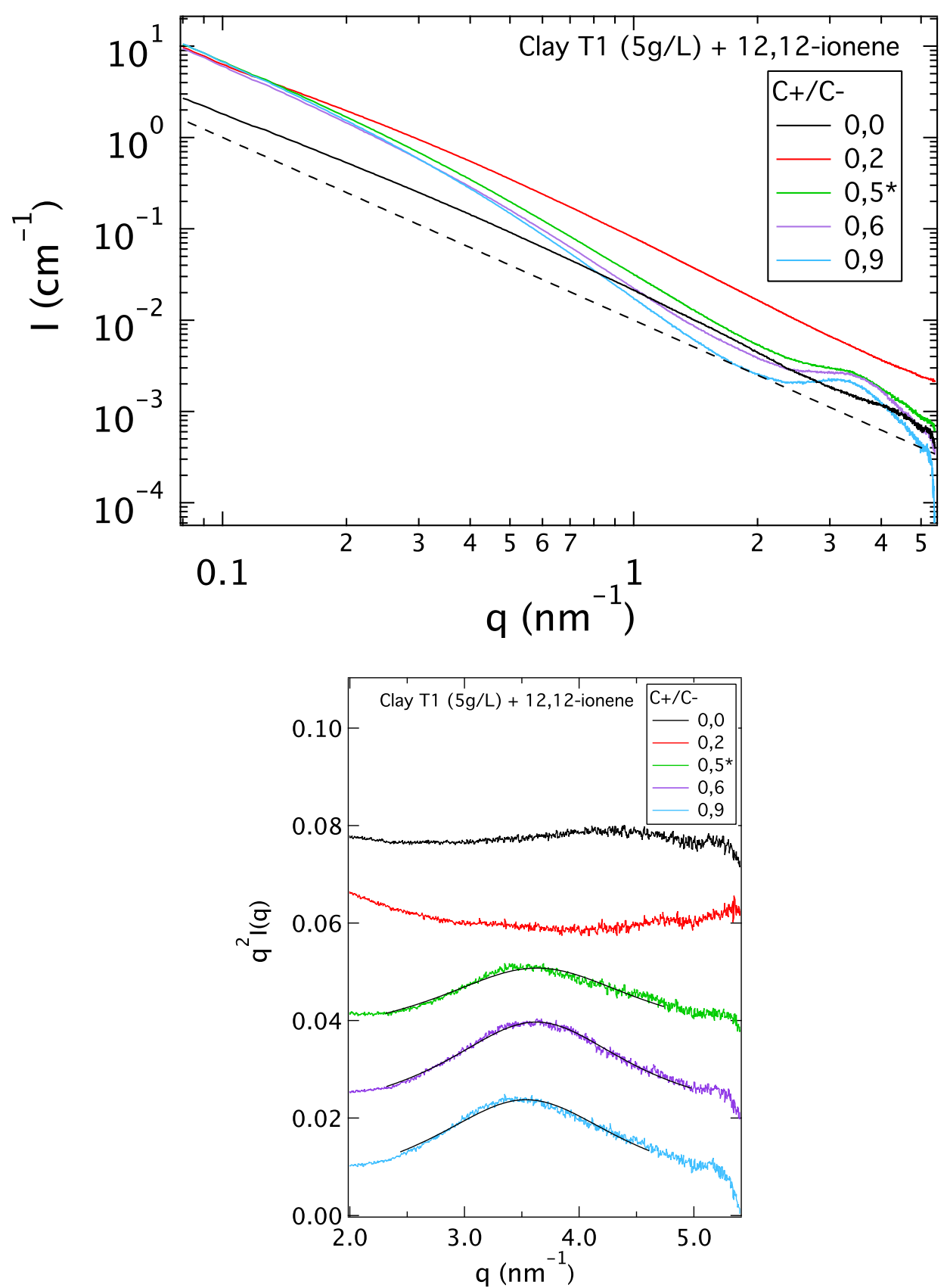

Figure 7: SAXS intensity versus the wave-vector $q$ for a series of suspensions of montmorillonite $\mathrm{T} 1$ clay particles (initial clay concentration of $5 \mathrm{~g} / \mathrm{L}$ ) aggregated by 12,12-ionene chains, at different ratios of $c^{+} / c^{-}$. The point of optimal aggregation $\left(c^{+} / c^{-}=0.5\right)$ is denoted by an asterisk. (top) $I(q)$ representation, where a guide to the eye corresponding to a $\mathrm{q}^{-2}$ dependence is shown as a dashed line and (bottom) $q^{2} I(q)$ representation, where the consecutive curves have been shifted along the y-scale for clarity. Lorentzian fits of the correlation peak at high $\mathrm{q}$ are shown for the last three curves in the series. 
the peak position and its FWHM do not change, however its intensity still grows and then remains constant (case of 12,12-ionenes) or indeed decreases again (case of 3,3-ionenes). Thus, as the chain content increases beyond $\left(c^{+} / c^{-}\right)_{o p t}$, more abundant stacks are formed at first and then their number stagnates or even decreases. Note that beyond $\left(c^{+} / c^{-}\right)_{\text {opt }}$, this variation in tactoid abundance has apparently no consequence on the aggregation efficiency, as assessed by turbidity measurements. At their level of sensitivity the aggregation efficiency remains constant beyond $\left(c^{+} / c^{-}\right)_{\text {opt }} \cdot{ }^{36}$ A notable feature of Figures 6 and 7 is the gradual decrease of scattered intensity in the Q-region preceding the stacking peak (best visible in the $I(q)$ representation, region between 0.5 and $\left.3 \mathrm{~nm}^{-1}\right)$. We are currently exploring its origin, which may be linked to the lateral disorder of individual platelets within the formed stacks.

\section{Effect of clay platelet size}

Figure 8 features a comparison of SAXS spectra for clay particles of two sizes $(\mathrm{T} 1=490 \mathrm{~nm}$ and $\mathrm{T} 2=240 \mathrm{~nm})$, flocculated by $3,3-$ and 6,6 -ionenes, at $\left(c^{+} / c^{-}\right)_{\text {opt }}$. As a reminder, the length of the extended ionene chains was estimated to vary between 100 and $300 \mathrm{~nm}$. Note that $\left(c^{+} / c^{-}\right)_{\text {opt }}$ was independent of clay size in case of 3,3-ionenes, but clay size dependent for other ionenes, leading to higher $\left(c^{+} / c^{-}\right)_{\text {opt }}$ as the clay size decreased. Figure 8 shows clearly that regular clay stacking in the aggregates formed is less probable as the clay size decreases and this for any chain charge density. The difference is particularly marked for 6,6-ionenes: optimal aggregation occurs for a significantly higher ionene content in the case of T2 clay particles, $\left(c^{+} / c^{-}\right)_{o p t}=0.7$, yet the extent of regular stacking is very small in comparison to T1 aggregates for which $\left(c^{+} / c^{-}\right)_{\text {opt }}=0.4$. It is known that stacking is more frequent for larger clay platelets, as seen through residual clay stacking in pristine clay suspensions. ${ }^{25,52}$ 

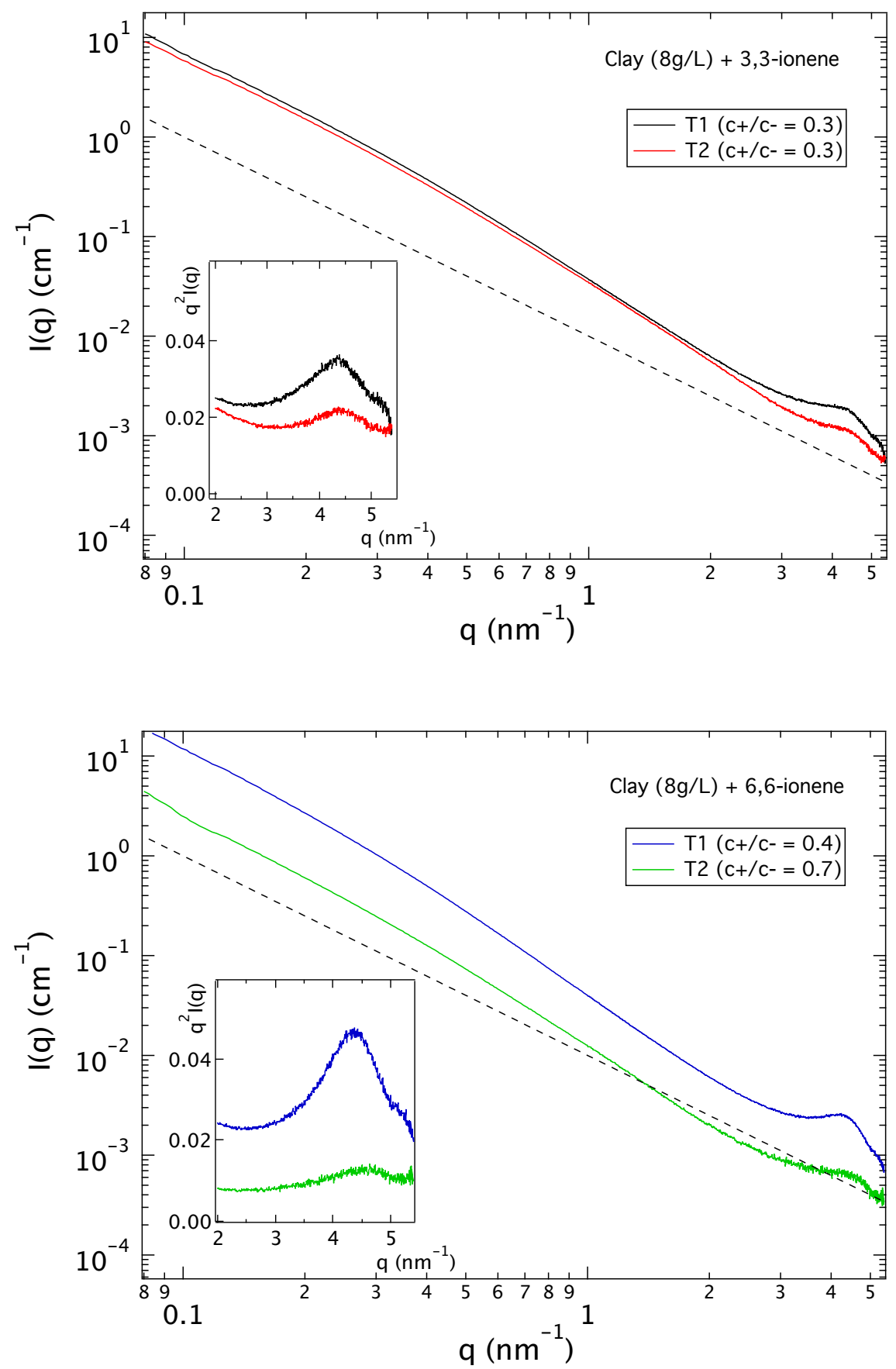

Figure 8: SAXS intensity versus the wave-vector q for suspensions of clay particles of two different sizes $(\mathrm{T} 1=490 \mathrm{~nm}$ and $\mathrm{T} 2=240 \mathrm{~nm}$ ), aggregated by: (top) 3,3-ionene chains and (bottom) 6,6-ionene chains. In each case, the data is shown at $\left(c^{+} / c^{-}\right)_{\text {opt }}$. 


\section{Tactoid structure and polyelectrolyte chain conformation}

The conformation of ionene polyelectrolyte chains in the systems studied is an important departure point for a general picture of ionene-clay tactoids, their formation and structure. Here, the most pertinent quantity reflecting the conformation is the polyelectrolyte persistence length, with its intrinsic and electrostatic contributions. ${ }^{53-55}$ The latter contribution reflects the repulsion of charges on the chain backbone. It is subject to electrostatic screening and thus varies as a function of the ionic strength, usually expressed in terms of the Debye length, $r_{D} \cdot 53,56$

The majority of our systems, as measured by SAXS, corresponds to clay concentrations of $5 \mathrm{~g} / \mathrm{L}\left(c_{\mathrm{Na}^{+}}=0.005 \mathrm{M}\right)$. Considering for simplicity the point of $c^{+} / c^{-}=1\left(c_{\mathrm{Na}^{+}}=c_{\mathrm{Br}^{-}}=0.005 \mathrm{M}\right)$, this leads to a Debye length of $\sim 4 \mathrm{~nm}$. For the most concentrated systems analysed $(27 \mathrm{~g} / \mathrm{L}$, SANS samples), the Debye length decreases to $\sim 2 \mathrm{~nm}$. Table 3 summarises the persistence lengths for the three types of ionenes used, at the above two concentrations. The electrostatic contribution to the persistence length is calculated on the basis of the Odijk-Skolnick-Fixman (OSF) theory. ${ }^{54,55}$ The OSF theory is known to be valid mainly at low ionic strengths (the case here), though a relatively recent study, on polyelectrolyte with precisely located charges as in ionenes, has reported a wide range of validity. ${ }^{57}$ For completeness, the intrinsic contribution to the persistence length for ionenes can be estimated from the stiffness of an uncharged hydrocarbon chain, which extends to approximately 4 methylene units, thus $0.5 \mathrm{~nm} .{ }^{51,58}$

To begin with, Table 3 allows us to conclude that the persistence length of 12,12-ionenes is closely comparable to the charge spacing on the 12,12 -ionene chain at the $5 \mathrm{~g} / \mathrm{L}$ clay concentration $(1 \mathrm{~nm})$. Some degree of undulation of the 12,12-ionene chains within the tactoid is thus indeed possible at this concentration and is consistent with the increased tactoid stacking distance as observed by SAXS. As we concentrate the clay system, the persistence length of any given type of ionene will decrease, thus potentially allowing more undulation within the tactoid. This is indeed observed for the 12,12-ionene case, as shown by the displacement of the stacking peak in Figure 4 (bottom). No undulation is however 
seen for tactoids with 3,3- and 6,6-ionenes. This is in part due to the significant persistence length of the highly charged 3,3-ionene chains: 6 times larger than the charge separation on the chain even at $27 \mathrm{~g} / \mathrm{L}$. Further, even if persistence length would allow undulation, i.e. $1_{p} / \mathrm{a}$ approaching 1 in Table 3 as is the case of 6,6-ionene at $27 \mathrm{~g} / \mathrm{L}$, the relative charge separations on the ionene chain and the clay surface have to be favourable. As the charge separation on the 6,6-ionene chain is comparable to that on the clay surface, a small persistence length of the chain does not lead to undulation. This is seen from the constant stacking distance within the tactoids, as we concentrate the system - refer back to Figure 4 (center). This is an important observation, highlighting the crucial role of the charge separation match/mismatch between the polyelectrolyte chain and the clay surface for the structure of the tactoid.

Table 3: Overview of the persistence lengths of ionene polymers at the experimental conditions used. $a$ is the charge separation on the ionene backbone, $l_{e}^{O S F}$ is the electrostatic contribution to the persistance length calculated according to the Odijk-Skolnick-Fixman (OSF) theory as $l_{e}^{O S F}=l_{B} r_{D}^{2} / 4 a^{2}$, where $l_{B}$ is the Bjerrum length and $r_{D}$ is the Debye length. ${ }^{53} l_{p} / a$ is the ratio of the total persistence length (including an intrinsic persistence length contribution of $0.5 \mathrm{~nm}$ ) and the charge separation on the ionene backbone.

\begin{tabular}{|c||c|cc|cc|}
\hline Ionene & \multirow{2}{*}{} & \multicolumn{2}{|c|}{$\mathrm{c}_{\text {clay }}=5 \mathrm{~g} / \mathrm{L}, \mathrm{r}_{D}=4.3 \mathrm{~nm}$} & \multicolumn{2}{c|}{$\mathrm{c}_{\text {clay }}=27 \mathrm{~g} / \mathrm{L}, \mathrm{r}_{D}=1.9 \mathrm{~nm}$} \\
& $\mathrm{a}(\mathrm{nm})$ & $\mathrm{l}_{e}$ OSF $(\mathrm{nm})$ & $\mathrm{l}_{p} / \mathrm{a}$ & $\mathrm{l}_{e}$ OSF $(\mathrm{nm})$ & $\mathrm{l}_{p} / \mathrm{a}$ \\
\hline \hline 3,3-ionene & 0.500 & 13 & 27 & 2.5 & 6 \\
6,6-ionene & 0.870 & 4 & 6 & 0.8 & 1.5 \\
12,12-ionene & 1.625 & 1 & 1 & 0.2 & 0.5 \\
\hline
\end{tabular}




\section{Conclusion}

We have investigated the nanoscale structure of clay aggregates formed in the presence of ionene polymers, focusing on the effects of clay/ionene relative charge densities and the polymer conformation. The nanoscale features of the formed clay aggregates are dominated by the presence of a stacking peak, giving clear evidence for the formation of clay tactoids, i.e. a face-to-face aggregation geometry of the clay platelets. The chain charge density of ionenes influences the stacking repeat distance within the clay tactoids, but also the extent of stacking and abundance of the tactoids, as reflected in the width of the stacking peak and its intensity, respectively. We may distinguish two regimes as a function of clay and ionene polymer charge densities, $\rho_{c}$ and $\rho_{p}$ respectively. The first regime applies to $\rho_{p}>\rho_{c}$ and $\rho_{p} \sim \rho_{c}$, i.e. for highly and "matching" charged chains. Under these conditions the intercalated chains lie in a flat conformation within the tactoids, irrespective of the ionic strength (within the range studied, i.e. up to 0.05M NaBr). For weakly charged chains, $\rho_{p}<\rho_{c}$, undulation of the ionene chains within the tactoid is seen. The degree of undulation increases with ionic strength, due to the decreasing persistence length of the ionene chains. It would be possible to extend these studies to higher ionic strengths, using a monovalent salt, to trace the influence of the amount of adsorbed polymer chains on the tactoid formation. For example, a maximum in the polymer adsorption on an oppositely charged surface has been reported as a function of the ionic strength. ${ }^{14}$ Overall however, the effect of monovalent salt has a complicated response in these systems. ${ }^{11}$ Finally, the system corresponding to the closest match in charge separations on the clay surface and on the polymer chain $(6,6$-ionene, $\rho_{p} \sim \rho_{c}$ ) features here the highest abundance of tactoids. It equally coincides with the highest macroscopic density as deduced from simple visual inspection of sediment volumes. However the extent of stacking within tactoids for this "optimal" system is not any higher than for the other systems.

More generally, we have observed tactoid formation in the aggregation of clays by inorganic salts ${ }^{4}$ as well as by ionene polymer chains, as is summarised in Figure 9 . The extent 
of stacking seems more significant for tactoids formed in the presence of inorganic salts (narrower peaks), but remains of the order of 10 layers per tactoid. The origin of this stacking limit remains unclear and subject to further study. ${ }^{59}$ While clay tactoids formed in the presence of inorganic salts feature a salt-independent stacking distance of approximately $1.9 \mathrm{~nm}$, equivalent of three water layers in-between adjacent clay surfaces, the ionene-clay tactoids on the other hand feature a variable stacking distance, tuneable via the polymer chain charge density (as well as the ionic strength). However, tactoid formation is not a universal feature of aggregation for a given clay system. As we have seen on the example of other charged polymer chains (PDADMAC) (see SI File), both a bulkier polymer chain structure and/or a higher chain length, favouring chain wrapping and inter-particle bridging, can be at the origin of the loss of tactoid formation. Seen from a different angle, the interest behind ionene polymers can be both their simple structure but also their short length, which leads to a faster approach to equilibrium structures. This is a significant advantage, as non-equilibrium effects are in general extremely difficult to evaluate. ${ }^{11}$

Based on the experimental evidence presented here, regarding the structure of the clayionene tactoids, it is not possible to determine whether the tactoid formation is driven by enthalpic or entropic changes. While a widely accepted view is that an aggregation process of oppositely charged components in solution is driven by the enthalpic changes associated with the electrostatic attraction, in the recent years we see the emergence of a view focusing on the entropic changes arising from the release of the counterions of the two components as the possible driving force. ${ }^{60,61}$ Both components, clay colloids and polyelectrolyte chains in our case, bring into the final system a population of charge-compensating counterions. While calorimetric techniques could inform us most directly on the enthalpic changes of the aggregation process, experimental probes for the counterion release are less obvious. We consider NMR-based techniques to be the most promising in this respect. Should the nature of the counter ion influence the aggregation process, it may be particularly relevant to investigate the aggregation behaviour of clays exchanged initially with multivalent, as 


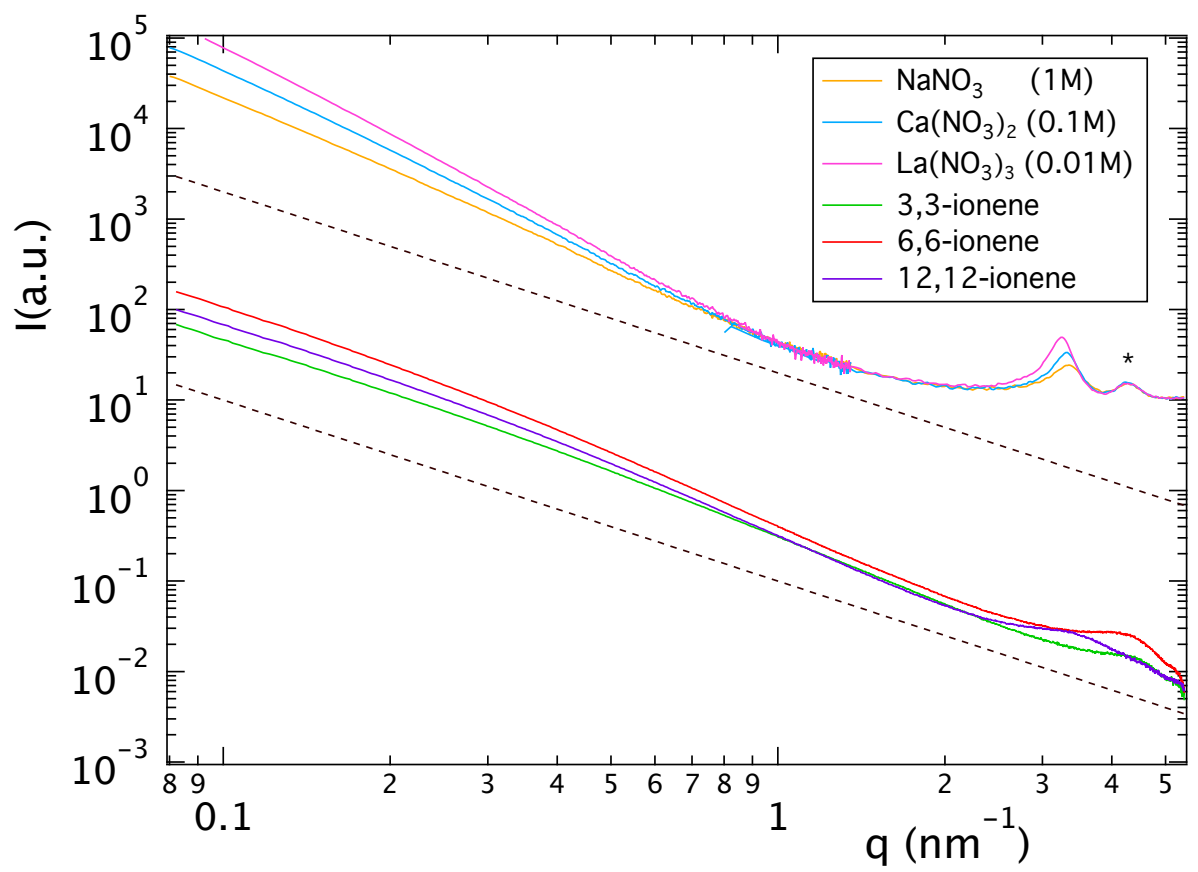

Figure 9: Comparison of SAXS signal of montmorillonite clay aggregates (T1 size) formed in the presence of inorganic salts (initial clay concentration of $2 \mathrm{~g} / \mathrm{L}, \mathrm{Na}$ counter ion) ${ }^{4}$ and by a series of ionenes (initial clay concentration of $5 \mathrm{~g} / \mathrm{L}, \mathrm{Na}$ counter ion, replotted data from Figure 2). Peak marked by asterisk (at $4.3 \mathrm{~nm}^{-1}$ in the upper data sets) is a parasitic peak from Kapton windows of the sample cell. 
opposed to monovalent, compensating cations. The release of multivalent ions from the clay component upon addition of charged polymer chains is likely to be significantly different, especially as pre-formation of tactoids in the initial clay suspension will take place. ${ }^{45,59}$

In conclusion, the interest behind the clay-ionene system, which features clay stacking, is the possibility to tune and assess, via the stacking peak characteristics, the aggregate density at the nanoscale. While tactoids are the most dense clay aggregates at this scale, the ultimate question is how and whether their presence influences the density of the aggregate at larger scales. We note that the ionene content for which the stacking peak is the most intense does not coincide with the point of optimal aggregation as deduced from turbidity measurements, it is located systematically at higher $c^{+} / c^{-}$. Therefore understanding the macroscopic sedimentation behaviour of the aggregates cannot rely only on nanoscale features and a multi-scale characterisation of the aggregate is indispensable. Our overall approach is thus to link the existing scattering results to those of X-ray imaging techniques, which extend the structural characterisation across several decades in spatial scale, as recently shown. ${ }^{4,62}$ This multi-scale approach could also be applied to analyse aggregate dynamics under controlled conditions of applied shear, in order to isolate the scale at which the shearinduced reorganisation of the aggregates takes place.

\section{Acknowledgement}

The authors thank Sofia Housni and Patrick Davidson for their assistance during X-ray scattering measurements at the ESRF, Fabrice Cousin and Sophie Combet for their help during neutron scattering experiments at the Laboratoire Léon Brillouin.

\section{Supporting Information Available}

Supplementary Information contains SAXS data for clay aggregates formed with PDADMAC polymer chains.

This material is available free of charge via the Internet at http://pubs . acs . org/. 


\section{References}

(1) Bergaya, F.; Lagaly, G.; Eds, Handbook of Clay Science; Elsevier: New York, 2006.

(2) Lagaly, G.; Ziesmer, S. Colloid chemistry of clay minerals: the coagulation of montmorillonite dispersions. Adv. Colloid Interface Sci. 2003, 100-102, 105-128.

(3) Shalkevich, A.; Stradner, A.; Bhat, S. K.; Muller, F.; Schurtenberger, P. Cluster, glass, and gel formation and viscoelastic phase separation in aqueous clay suspensions. Langmuir 2007, 23, 3570-3580.

(4) Michot, L. J.; Bihannic, I.; Thomas, F.; Lartiges, B. S.; Waldvogel, Y.; Caillet, C.; Thieme, J.; Funari, S. S.; Levitz, P. Coagulation of Na-montmorillonite by inorganic cations at neutral ph. A combined transmission X-ray microscopy, small angle and wide angle x-ray scattering study. Langmuir 2013, 29, 3500-3510.

(5) Anovitz, L. M.; Zhang, X.; Soltis, J.; Nakouzi, E.; Krzysko, A. J.; Chun, J.; Schenter, G. K.; Graham, T. R.; Rosso, K. M.; De Yoreo, J. J.; Stack, A. G.; Bleuel, M.; Gagnon, C.; Mildner, D. F. R.; Ilavsky, J. and Kuzmenko, I., Effects of ionic strength, salt, and pH on aggregation of boehmite nanocrystals: Tumbler small-angle neutron and X-ray scattering andimaging analysis. Langmuir 2018, 34, 15839-15853.

(6) Lu, H.; Xiang, L.; Cui, X.; Liu, J.; Wang, Y.; Narain, R.; Zeng, H. Molecular weight dependence of synthetic glycopolymers on flocculation and dewatering of fine particles. Langmuir 2016, 32, 11615-11622.

(7) Bolto, B.; Gregory, J. Organic polyelectrolytes in water treatment. Water Research 2007, 41, 2301-2324.

(8) Petzold, G.; Schwarz, S. In Polyelectrolyte complexes in the dispersed and solid state II: Application aspects; Muller, M,, Ed.; Adv. Polym. Sci.; 2014; Vol. 256; pp 25-65.

(9) Cosgrove, T.; Ed., Colloid science: principles, methods and applications; Wiley, 2010. 
(10) Lekkerkerker, H. N. W.; Tuinier, R. Lecture notes in physics: colloids and the depletion interaction; Springer, 2011; Vol. 833.

(11) Forsman, J. Surface forces in electrolytes containing polyions and oppositely charged surfaces. Current Opinion In Colloid \& Interface Science 2017, 27, 57-62.

(12) Szilagyi, I.; Trefalt, G.; Tiraferri, A.; Maroni, P.; Borkovec, M. Polyelectrolyte adsorption, interparticle forces, and colloidal aggregation. Soft Matter 2014, 10, 2479-2502.

(13) Podgornik, R.; Licer, M. Polyelectrolyte bridging interactions between charged macromolecules. Current Opinion In Colloid \& Interface Science 2006, 11, 273-279.

(14) Xie, F.; Nylander, T.; Piculell, L.; Utsel, S.; Wagberg, L.; Akesson, T.; Forsman, J. Polyelectrolyte Adsorption on Solid Surfaces: Theoretical Predictions and Experimental Measurements. Langmuir 2013, 29, 12421-12431.

(15) Boroudjerdi, H.; Kim, Y.; Naji, A.; Netz, R.; Schlagberger, X.; Serr, A. Statics and dynamics of strongly charged soft matter. Physics Reports-Review Section Of Physics Letters 2005, 416, 129-199.

(16) Cooper, C.; Dubin, P.; Kayitmazer, A.; Turksen, S. Polyelectrolyte-protein complexes. Current Opinion In Colloid \& Interface Science 2005, 10, 52-78.

(17) Ulrich, S.; Seijo, M.; Stoll, S. The many facets of polyelectrolytes and oppositely charged macroions complex formation. Current Opinion In Colloid \& Interface Science 2006, $11,268-272$.

(18) Jonsson, M.; Linse, P. Polyelectrolyte-macroion complexation. I. Effect of linear charge density, chain length, and macroion charge. Journal Of Chemical Physics 2001, 115, $3406-3418$.

(19) Jonsson, M.; Linse, P. Polyelectrolyte-macroion complexation. II. Effect of chain flexibility. Journal Of Chemical Physics 2001, 115, 10975-10985. 
(20) Dzubiella, J.; Moreira, A. G.; Pincus, P. A. Polyelectrolyte-colloid complexes: Polarizability and effective interaction. Macromolecules 2003, 36, 1741-1752.

(21) Messina, R. Electrostatics in soft matter. Journal Of Physics-Condensed Matter 2009, 21.

(22) Winkler, R. G.; Cherstvy, A. G. In Polyelectrolyte complexes in the dispersed and solid state $i$ : principles and theory; Muller, M,, Ed.; Advances in Polymer Science; 2014; Vol. $255 ;$ pp $1-56$.

(23) Turesson, M.; Forsman, J.; Akesson, T. Surface forces mediated by charged polymers: Effects of intrinsic chain stiffness. Langmuir 2006, 22, 5734-5741.

(24) Bohinc, K.; Grime, J. M. A.; Lue, L. The interactions between charged colloids with rod-like counterions. Soft Matter 2012, 8, 5679-5686.

(25) Paineau, E.; Bihannic, I.; Baravian, C.; Philippe, A.-M.; Davidson, P.; Levitz, P.; Funari, S. S.; Rochas, C.; Michot, L. J. Aqueous suspensions of natural swelling clay minerals. 1. Structure and electrostatic interactions. Langmuir 2011, 27, 5562-5573.

(26) Michot, L.; Bihannic, I.; Porsch, K.; Maddi, S.; Baravian, C.; Mougel, J.; Levitz, P. Phase diagrams of Wyoming Na-montmorillonite clay. Influence of particle anisotropy. Langmuir 2004, 20, 10829-10837.

(27) Noguchi, H.; Rembaum, A. Ionene polymers. 2. Formation of cyclic and linear compounds or polymers from n,n,n',n'-tetramethyl-alpha,omega-diaminoalkanes and alpha,omega-dibromoalkanes. J. Polym. Sci. Pol. Lett. 1969, 7, 383-394.

(28) Malikova, N.; Cebasek, S.; Glenisson, V.; Bhowmik, D.; Carrot, G.; Vlachy, V. Aqueous solutions of ionenes: Interactions and counterion specific effects as seen by neutron scattering. Phys. Chem. Chem. Phys. 2012, 14, 12898-12904. 
(29) Malikova, N.; Rollet, A.-L.; Cebasek, S.; Tomsic, M.; Vlachy, V. On the crossroads of current polyelectrolyte theory and counterion-specific effects. Phys. Chem. Chem. Phys. 2015, 17, 5650-5658.

(30) Raskop, M. P.; Grimm, A.; Seubert, A. Polystyrene immobilized ionenes as novel stationary phase for ion chromatography. Microchim. Acta 2007, 158, 85-94.

(31) Erdmenger, T.; Perevyazko, I.; Vitz, J.; Pavlov, G.; Schubert, U. S. Microwave-assisted synthesis of imidazolium ionenes and their application as humidity absorbers. J. Mater. Chem. 2010, 20, 3583-3585.

(32) Berezovska, I. S.; Yanishpolskii, V. V.; Tertykh, V. A.; Burmistr, M. V.; Sukhyy, K. M. Role of ionene in composition of porous structure of template-synthesized silicas. $J$. Therm. Anal. Calorim. 2006, 86, 93-96.

(33) Narita, T.; Ohtakeyama, R.; Nishino, M.; Gong, J.; Osada, Y. Effects of charge density and hydrophobicity of ionene polymer on cell binding and viability. Colloid and Polymer Science 2000, 278, 884-887.

(34) Kourai, H.; Yabuhara, T.; Shirai, A.; Maeda, T.; Nagamune, H. Syntheses and antimicrobial activities of a series of new bis-quaternary ammonium compounds. European Journal of Medicinal Chemistry 2006, 41, 437-444.

(35) Boyd, S. A.; Johnston, C. T.; Laird, D. A.; Teppen, B. J.; Li, H. In Biophysico-chemical processes of anthropogenic organic compounds in environmental systems; Xing, B and Senesi, N and Huang, PM,, Ed.; Wiley-IUPAC Series in Biophysico-Chemical Processes in Environmental Systems; 2011; pp 51-71.

(36) Sakhawoth, Y.; Michot, L. J.; Levitz, P.; Malikova, N. Flocculation of clay colloids induced by model polyelectrolytes: effects of relative charge density and size. Chem. Phys. Chem. 2017, 18, 2756-2765. 
(37) Bremmell, K.; Jameson, G.; Biggs, S. Polyelectrolyte adsorption at the solid/liquid interface - Interaction forces and stability. Colloid Surface A 1998, 139, 199-211.

(38) Claesson, P.; Poptoshev, E.; Blomberg, E.; Dedinaite, A. Polyelectrolyte-mediated surface interactions. Adv. Colloid Interface Sci. 2005, 114, 173-187.

(39) Čebašek, S.; Seručnik, M.; Vlachy, V. Presence of hydrophobic groups may modify the specific ion effect in aqueous polyelectrolyte solutions. J. Phys. Chem. B 2013, 117, $3682-3688$.

(40) Čebašek, S.; Lukšič, M.; Pohar, C.; Vlachy, V. Thermodynamics of dilution and the Hofmeister series in aqueous solutions of aliphatic ionenes with halide counterions. $J$. Chem. Eng. Data 2011, 56, 1282-1292.

(41) Layman, J. M.; Borgerding, E. M.; Williams, S. R.; Heath, W. H.; Long, T. E. Synthesis and characterization of aliphatic ammonium ionenes: Aqueous size exclusion chromatography for absolute molecular weight characterization. Macromolecules $\mathbf{2 0 0 8 ,}$ 41, 4635-4641.

(42) Williams, S. R.; Borgerding, E. M.; Layman, J. M.; Wang, W.; Winey, K. I.; Long, T. E. Synthesis and characterization of well-defined 12,12-ammonium ionenes: Evaluating mechanical properties as a function of molecular weight. Macromolecules 2008, 41, $5216-5222$.

(43) Cousin, F.; Cabuil, V.; Levitz, P. Magnetic colloidal particles as probes for the determination of the structure of laponite suspensions. Langmuir 2002, 18, 1466-1473.

(44) Grillo, I. In Soft-matter characterization; Borsali, R., Pecora, R., Eds.; Springer, 2008; pp $725-777$.

(45) Segad, M.; Jonsson, B.; Cabane, B. Tactoid formation in montmorillonite. J. Phys. Chem. C 2012, 116, 25425-25433. 
(46) Pedreira-Segade, U.; Michot, L. J.; Daniel, I. Effects of salinity on the adsorption of nucleotides onto phyllosilicates. Phys. Chem. Chem. Phys. 2018, 20, 1938-1952.

(47) Drits, V.; Srodon, J.; Eberl, D. XRD measurement of mean crystalline thickness of illite and illite/smectite: Reappraisal of the Kubler index and the Scherrer equation. Clay Clay Miner. 1997, 45, 461-475.

(48) Jaboyedoff, M.; Kubler, B.; Thelin, P. An empirical Scherrer equation for weakly swelling mixed-layer minerals, especially illite-smectite. Clay Miner. 1999, 34, 601617.

(49) Ferrage, E.; Lanson, B.; Malikova, N.; Plancon, A.; Sakharov, B.; Drits, V. New insights on the distribution of interlayer water in bi-hydrated smectite from X-ray diffraction profile modeling of 001 reflections. Chem. Mater. 2005, 17, 3499-3512.

(50) N. Malikova, V. Marry, J.-F. Dufréche, C. Simon, P. Turq and E. Giffaut, Temperature effect in a montmorillonite clay at low hydration - microscopic simulation. Mol.Phys. 2004, 102, 1965-1977.

(51) Bhowmik, D.; Malikova, N.; Meriguet, G.; Bernard, O.; Teixeira, J.; Turq, P. Aqueous solutions of tetraalkylammonium halides: ion hydration, dynamics and ion-ion interactions in light of steric effects. Phys. Chem. Chem. Phys. 2014, 16, 13447-13457.

(52) Baravian, C.; Michot, L. J.; Paineau, E.; Bihannic, I.; Davidson, P.; Imperor-Clerc, M.; Belamie, E.; Levitz, P. An effective geometrical approach to the structure of colloidal suspensions of very anisometric particles. EPL 2010, 90.

(53) Dautzenberg, H.; Jager, W.; Kotz, J.; Philipp, B.; Seidel, C.; Stscherbina, D. Polyelectrolytes. Formation, Characterisation and Application; Hanser, Munich, 1994.

(54) Barrat, J.; Joanny, J. Persistence length of polyelectrolyte chains. Europhysics Letters 1993, 24, 333-338. 
(55) Ha, B.-Y.; Thirumalai, D. Electrostatic Persistence length of a polyelectrolyte chain. Macromolecules 1995, 28, 577-581.

(56) Robinson, R. A.; Stokes, R. H. Electrolyte solutions; Dover publications, New York, 2002.

(57) Murnen, H. K.; Rosales, A. M.; Dobrynin, A. V.; Zuckermann, R. N.; Segalman, R. A. Persistence length of polyelectrolytes with precisely located charges. Soft Matter 2013, 9, 90-98.

(58) Rawicz, W.; Olbrich, K.; McIntosh, T.; Needham, D.; Evans, E. Effect of chain length and unsaturation on elasticity of lipid bilayers. Biophysical Journal 2000, 79, 328-339.

(59) Thuresson, A.; Ullner, M.; Akesson, T.; Labbez, C.; Jonsson, B. Monte Carlo simulations of parallel charged platelets as an approach to tactoid formation in clay. Langmuir 2013, 29, 9216-9223.

(60) Rathee, V. S.; Sidky, H.; Sikora, B. J.; Whitmer, J. K. Role of Associative Charging in the Entropy-Energy Balance of Polyelectrolyte Complexes. Journal of the American Chemical Society 2018, 140, 15319-15328.

(61) Muthukumar, M. 50th Anniversary Perspective: A Perspective on Polyelectrolyte Solutions. Macromolecules 2017, 50, 9528-9560.

(62) Brisard, S.; Chae, R. S.; Bihannic, I.; Michot, L.; Guttmann, P.; Thieme, J.; Schneider, G.; Monteiro, P. J. M.; Levitz, P. Morphological quantification of hierarchical geomaterials by X-ray nano-CT bridges the gap from nano to micro length scales. Am. Mineral. 2012, 97, 480-483. 


\section{Graphical TOC Entry}

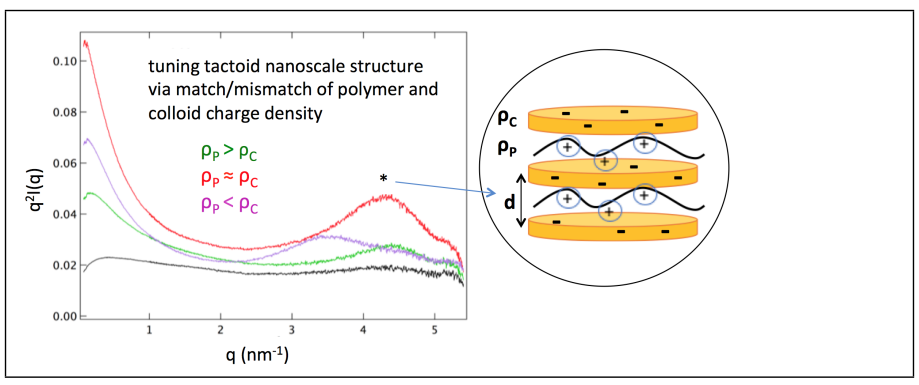

